\title{
O jornalista enquanto herói: uma proposta para análise das representações do jornalismo no cinema
}

\author{
VITOR LUIZ MENEZES GOMES \\ Centro Universitário Fluminense (Uniflu) - E-mail: vitormenezes@uniflu.edu.br \\ Jornalista e professor, mestre em Sociologia pelo Instituto Universitário de Pesquisas do Rio de Janeiro. \\ Professor do Curso de Jornalismo do Uniflu - Campus II - Filosofia, em Campos dos Goytacazes (RJ).
}

\begin{abstract}
Resumo
As representações do jornalista no cinema têm sido estudadas por diferentes pesquisadores que buscam, por meio de metodologias de análise fílmica, ou por meio de ensaios impressionistas, reunir elementos que contribuam para o conhecimento acerca do ethos deste profissional. No Brasil, por exemplo, são consagradas as experiências de pesquisa de Christa Berger e de Stella Senra neste campo. $O$ artigo propõe um método de análise de filmes com esta mesma finalidade de estudo das representações do jornalista em obras cinematográficas, com a peculiaridade de utilizar a chamada trajetória do herói, especialmente para o caso de roteiros guiados pelo formato da narrativa clássica, como preconizado por autores como Joseph Campbell e Christopher Vogler.
\end{abstract}

\section{Palavras-chave}

Jornalismo; Ethos Profissional; Cinema.

\begin{abstract}
The representations of the journalist in film have been studied by different researchers who seek, through methodologies of film analysis, or by testing impressionists together elements that contribute to the understanding of the ethos of the profession. In Brazil, for example, are devoted to research experiences Christa Berger and Stella Senra this field. The paper proposes a method of analysis of films with the same purpose for the study of representations of the journalist in cinematographic works, with the peculiarity of using the call path of the hero, especially for the case of guided tours by classical narrative format, as recommended by authors such as Joseph Campbell and Christopher Vogler.
\end{abstract}

\section{Keywords}

Journalism; Professional ethos; Cinema.

Artigo recebido em 10/03/2013

Aprovado em 21/04/2013 
em sido suficientemente demonstrada a relevância e as contribuições que
podem oferecer os estudos das representações sociais ${ }^{1}$ nos produtos culturais
de massa - ou nos produtos da indústria cultural, para utilizar uma expressão mais cara à Escola Crítica. Dada a sua abrangência sobre uma larga audiência e seu grande volume de produção, estes produtos, ao mesmo tempo em que se alimentam de bens simbólicos produzidos na chamada vida real, se tornam, eles próprios, produtores de novas formas de pertencimento e atribuição de sentido à vida ou a aspectos da vida. Um dos mais poderosos instrumentos desta indústria é o Cinema, entendido aqui não apenas como objeto de arte, mas, sobretudo, como uma instância produtora ininterrupta de conteúdos para um grande mercado consumidor de entretenimento e arte.

São diversas as possibilidades de abordagem. Seja para compreender uma época, uma determinada mentalidade, um costume, uma dada coletividade, um papel social, um personagem histórico, o cinema se mostra fonte quase sempre acessível (e reproduzível, diferentemente dos estudos empíricos) e rica na produção de significações, sem que, no entanto, como em qualquer pesquisa, sejam desconsideradas as limitações e dificuldades metodológicas - algumas das quais serão abordadas adiante, em relação ao objeto deste artigo. Assim é que, somente para ater-se a exemplos recentes encontrados em revistas acadêmicas do campo da Comunicação Social no Brasil, são produzidos artigos para tratar de temas como a representação do gângster no cinema (CAMPOS SILVA e SANTOS SILVA: 2010), a identificação de elementos constituintes do nacionalismo brasileiro no cinema produzido no País (CARVALHO: 2004), as subjetividades presentes no filme "Clube da Luta" (BREA: 2006), o modo como a figura de Jesus Cristo foi representada em diferentes filmes, com uma proposta metodológica para este tipo específico de estudo (VADICO: 2008), ou a representação do amor na sociedade de consumo, como apresentado pelo cinema (RÜDIGER: 2009).

Mas uma área tem, notadamente, se utilizado de forma profícua do cinema como

1 Aqui se entende "representações sociais" como preconizado pela Sociologia de Durkheim, do mesmo modo como trabalhado por Henrique Codato em "Cinema e representações sociais - alguns diálogos possíveis" (2010). 
fonte de interpretação e chave de acesso à realidade: aquela que estuda o ethos profissional, a identidade do trabalhador ou de um conjunto de trabalhadores, a ideia que fazem de si mesmos, a trajetória de formação histórica de uma determinada atividade laboral. No caso dos jornalistas, interesse específico deste artigo, esta produção também tem sido utilizada para descrever rotinas, identificar conflitos, situar demandas éticas, problematizar estereótipos. Um alentado esforço neste sentido foi empreendido pela pesquisa "O ofício do jornalista: da sala de redação à tela de cinema", coordenada por Christa Berger, que resultou no livro "Jornalismo no Cinema: filmografia e comentários" (Ed. UFRGS: 2002). Com o objetivo de reconhecer representações do jornalista e do jornalismo no cinema, os pesquisadores percorreram aproximadamente 25 mil sinopses de filmes, e encontraram em 785 delas indicações das presenças de personagens jornalistas, protagonistas ou secundários, em tramas que variavam entre ter o jornalismo como atividade central na narrativa ou como acessória destes filmes, 536 são norte-americanos. Passada uma década deste levantamento, não é implausível supor a significativa ampliação da produção de filmes com estas características. Poderiam ser adicionadas a esta lista diversas produções após 2003, ano seguinte à publicação da obra de Berger, que atenderiam à premissa de conter personagens jornalistas ou abordar o jornalismo como instituição, como, por exemplo, Confidencial (EUA, 2006) ${ }^{2}$, Cidade do Silêncio (EUA/Inglaterra, 2007), Intrigas de Estado (EUA, 2009), A Caçada (Bósnia-Herzegovina/Croácia/EUA, 2007), Boa Noite, Boa Sorte (EUA, 2005) e Capote (EUA, 2005).

A autora situa a existência de uma certa consolidação do segmento, tendo sido consagradas as expressões newspaper movie e journalism films, ratificando a relevância desta produção para a compreensão do papel do jornalista e do jornalismo. Não somente pelo volume, mas também por características inerentes à sua própria indústria, como argumenta Berger, foram os Estados Unidos os responsáveis por melhor traduzir (ou ajudar a construir) o imaginário em torno da profissão.

20 país de origem e o ano de produção dos filmes só aparecerão na primeira vez em que as obras forem citadas no artigo, excetuando-se os casos de reproduções de textos de outros autores. 
A obra organizada por Berger esquadrinha parte desta produção, por meio da reunião de artigos de pesquisadores que, como ela, se debruçam sobre as formas de representação de jornalistas no cinema. Deste modo, dezenas de filmes e personagens jornalistas são analisados pelos autores colaboradores da coletânea (Giba Assis Brasil, Ronaldo Henn, Tuio Becker, Flávio Maineri, Francisco Rüdiger, Rosa Nívea Pedroso, Adriana Achryver Kurtz, Karen Silvia Debértolis, Helena Kempf, Silvia Lisboa, Cláudia Rejane do Carmo, Fatimarlei Lunardelli, Maria Helena Weber e Luciano Miranda, aqui citados na ordem de aparição no sumário).

A obra organizada por Berger é tributária, por sua vez, de trabalhos como o de Stella Senra, autora de "O último jornalista - Imagens de cinema" (Estação Liberdade: 1997), que também pesquisou a construção do imaginário acerca da profissão do jornalista empreendida pelo cinema. A autora identificou, no jornalismo norteamericano do final do século XIX e início do século XX, as origens de alguns dos referenciais que compõem o estereótipo produzido pelo cinema - não sem a contribuição dos próprios jornalistas do mundo real - acerca da profíssão. Deste modo, de acordo com a sua leitura e a dos autores por ela consultados, o comportamento "mercenário" de muitos jornalistas teria origem no fato de que estes profissionais ganhavam, antes de uma maior profissionalização do ramo, por linha escrita, como freelancers, e portanto estariam em uma luta contínua com os editores por mais linhas e por mais dinheiro. A "ignorância" também atribuída ao personagem se daria em razão da "baixa extração social dos primeiros profissionais de imprensa e na ausência da exigência de qualquer formação prévia para o exercício do jornalismo" (SENRA, 1997: p. 47), o que atraía toda sorte de aventureiros.

Outra característica do personagem neste período, o "alcoolismo", seria "evidentemente uma herança do contexto boêmio em que viviam os profissionais da imprensa" (SENRA, 1997: p. 48). Este traço também seria representativo, segundo a autora, de um cenário de época em que o mundo masculino dominava a esfera pública e, consequentemente também o jornalismo - e aos homens seria dado o convívio 
boêmio como uma forma de solidariedade entre os integrantes de um "universo masculino reconhecido como superior" (SENRA, 1997: p. 49). Por fim, o não menos atribuído "cinismo", que teria origem na necessidade de encontrar um anteparo para enfrentar uma realidade cruel, "um modo de se defender dos rigores da realidade" (Idem).

Como não poderia desamparar seus heróis, todas estas características foram trabalhadas no cinema, na maioria dos casos, em favor da imagem do jornalista, diferentemente do que se poderia supor. Como demonstra Senra, o mercenarismo não poderia ser mau visto em um momento histórico de constituição do Capitalismo dos Estados Unidos, mas, antes, como o direito legítimo de qualquer indivíduo na disputa pela sobrevivência financeira. Além disso, a "miséria crônica" do jornalista acabava por reforçar o seu traço idealista, a do sujeito que, a despeito de ser mal remunerado, enfrenta a tudo e a todos em busca da verdade e da justiça. A atribuída ignorância acabava por conferir ao jornalista uma certa perspectiva ingênua em relação ao mundo, o que supostamente lhe permitiria registrar os fatos de modo acrítico, em atendimento da esperada objetividade do repórter. E o alcoolismo, assim como o cinismo, reforçariam a crença de que estes profissionais pertenciam a um mundo especial, que tinham que ser duros para cobrir a realidade do mundo e enfrentar, até mesmo com privações físicas e emocionais, as consequências da opção heróica de descobrir e relatar os acontecimentos para a sociedade.

Por meio da análise de vários filmes sobre jornalismo ou que tenham personagens jornalistas, Senra também discutiu em sua obra alguns outros traços associados à profissão, como o da já citada figura do herói, a do vocacionado, a do profissional em conflito ético, a do capaz de produzir relatos com objetividade, o que vive sob conturbadas relações familiares (sempre menos interessantes que o universo profissional), aquele em convívio permanente com um arsenal tecnológico que transforma o seu papel (a ponto de fazê-lo parecer ser passível de substituição por um "clone", como no caso dos apresentadores de televisão), o que manipula o papel do 
medo na constituição do pacto entre leitores e jornalismo, entre outros.

Outras iniciativas na área também têm mobilizado pesquisadores brasileiros. Cláudia Lago apresentou trabalho sobre "Ethos romântico jornalístico e cinema" durante o $5^{\circ}$ Encontro Nacional de Pesquisadores em Jornalismo, na Universidade Federal de Sergipe, em 2007. O texto é fruto do interesse da autora em entender a formação de um ethos romântico no exercício do jornalismo, como havia sido manifestado em artigo de 2003, apresentado durante XII Encontro Nacional da Associação de Programas de Pós Graduação em Comunicação ("De romântico e de louco... reflexões sobre o romantismo jornalístico"). No trabalho de 2007, Lago elege o filme Boa Noite, Boa Sorte para análise, encontrando nele os elementos que caracterizam o exercício romântico do jornalismo: "Os elementos do ethos romântico estão presentes em profusão [no filme]: o jornalismo como missão, a vocação que a tudo se sobrepõe, a busca da verdade, o individualismo do herói (mesmo com a equipe é ele que carrega o fardo das decisões e também das perseguições) e imprime sua marca de gênio individual no sistema que não é mais este" (LAGO: 2007).

A análise de Boa noite, boa sorte também foi o objeto de Ricardo Alexino Ferreira, que estabeleceu um paralelo desta obra com A Montanha dos Sete Abutres (EUA, 1951) no artigo "Do discurso frankfurtiano ao do newsmaking: a construção simbólica do jornalismo no cinema", de 2006. O autor se propôs a "entender a construção simbólica do jornalismo pelo cinema" nos dois filmes.

As duas obras têm discursos semelhantes, apesar de um aparente antagonismo, pois trazem em seu bojo uma pregação moral do que seria o bom jornalismo e o bom jornalista. Essa imagem idealizada trabalha com a ideia de que o fracasso ou falha nessas idealizações devem ser pagas com a morte de fato ou a morte simbólica. (FERREIRA: 2006).

O clássico de Billy Wilder, possivelmente, junto com Cidadão Kane (EUA: 1941), um dos mais estudados entre os journalism films, também foi utilizado como 
fonte primária por Isabel Travancas, em artigo de 2001, intitulado "Jornalista como personagem de cinema", que foi apresentado no Congresso da Intercom (Sociedade Brasileira de Estudos Interdisciplinares da Comunicação) daquele ano, em Campo Grande (MS). Além de A Montanha dos Sete Abutres, Travancas analisou No silêncio da cidade (EUA: 1956) e Todos os homens do Presidente (EUA: 1976). A pesquisadora registrou ter objetivos semelhantes aos que já foram apresentados aqui em relação a trabalhos do gênero: "discutir em que medida o cinema constrói estereótipos do jornalista, ora apresentando-o nas telas como bandido, ora como herói" (TRAVANCAS: 2001).

Já em "Cinema e Jornalismo: o melodrama e a tragédia moderna" (2008), Lisandro Nogueira explicita a aproximação das formas narrativas do cinema e do jornalismo, mostrando a semelhança de estratégias na busca de identificação do espectador. O artigo analisa especificamente o caso do filme Doces Poderes (Brasil: 1996), para demonstrar como este "se distancia do melodrama, se aproxima de um sentido de tragédia e critica os procedimentos objetivos do telejornalismo".

Também se ocupou da análise do cinema brasileiro, em sua relação com o jornalismo e os jornalistas, o pesquisador Valdir Baptista, que em artigo de 2007, apresentado no $5^{\circ}$ Encontro Nacional de Pesquisadores em Jornalismo, promovido pela SBPJor (Associação Brasileira de Pesquisadores em Jornalismo), procurou "estabelecer possibilidades de estudo desta mútua influência, que vão desde a forma como os jornalistas são representados na tela até ao exame das trajetórias de vida de jornalistas e cineastas que exerceram ou exercem ainda papel relevante em pelo menos uma das duas áreas", adicionando elementos para além da obra cinematográfica, considerando ainda o seu entorno e os seus produtores. Entre outras questões, o autor identificou que:

A evolução do papel do jornalista como personagem no cinema brasileiro já reflete a imbricação de novo tipo entre o jornalismo e o cinema. Antes do movimento do Cinema Novo, o jornalista era tratado, de modo geral, através do viés sensacionalista, isto é, com acento pejorativo e desqualificante da profissão, como em $O$ Pagador 
de Promessas (1962), de Anselmo Duarte, e Boca de Ouro (1962), de Nelson Pereira dos Santos, baseados em peças teatrais de grande sucesso, escritas, respectivamente, pelos dramaturgos Dias Gomes, marxista assumido, e pelo auto-intitulado "reacionário" (e jornalista) Nelson Rodrigues. Neles, os jornalistas (cujos papéis são secundários, mas determinantes nas tramas) seguem o estereótipo do sensacionalista que deseja se aproveitar de pessoas humildes para executar seu trabalho, num estilo semelhante ao do protagonista do célebre filme norte-americano A Montanha dos Sete Abutres (1956), do cineasta (e jornalista) Billy Wilder.” (BAPTISTA: 2007)

Outro modo de abordagem foi encontrado por Cláudio Cardoso. Além da presença de personagens jornalistas em filmes, ele procurou identificar, de modo mais amplo, o papel de aparatos das mídias no cinema (como televisão, fotografia, rádio, telefone, cartas). Em artigo de 2007, publicado pela Revista Famecos, o autor analisa o modo como o cinema retrata outras mídias, assim como jornalistas e o jornalismo, em diversos filmes - para citar alguns entre os mais clássicos: Cidadão Kane, A Montanha dos Sete Abutres, A Embriaguez do Sucesso (EUA: 1957), O Crepúsculo dos Deuses (EUA: 1950), Blow-up, depois daquele Beijo (Itália/Reino Unido: 1966), Todos os Homens do Presidente - e conclui, por exemplo, que o perfil do jornalista é assimilado pelo cinema de maneira a acentuar os seus traços geradores de conflitos, no sentido de angariar atenção da audiência.

O perfil do jornalista na imaginação criativa do cinema se apresenta por meio de uma legião de personagens, cujo caráter e temperamento se mostram diferenciados, mas podemos perceber que são enfatizados os traços que possam atrair de maneira mais efetiva a audiência. Então, temos a elaboração de perfis psicológicos, repertórios de linguagem e um conjunto de atitudes e comportamentos que deverão refletir a parte altruísta e a parte egoísta dos seres humanos, os níveis elevados e os níveis mais rasteiros porque o diálogo entre os opostos pode gerar efeitos lucrativos junto ao espectador. (PAIVA: 2007)

Entre os personagens jornalistas, um, em especial, atende com perfeição à demanda por ação e trajetória na narrativa clássica: os correspondentes estrangeiros. 
Filmes com estes tipos foram analisados pelo pesquisador Julio César Lobo, da Universidade Federal da Bahia. Sua tese de doutoramento pela Universidade de São Paulo - "Rede de representações (configurações do correspondente estrangeiro em situações de comunicação intercultural no cinema internacional)" -, de 2002, reúne análises dos filmes Passageiro, Profissão: Repórter (França, EUA, Espanha, Itália: 1975), Os Gritos do Silêncio (Reino Unido/EUA: 1984), Os Boinas Verdes (EUA: 1968), O ano em que vivemos em perigo (Austrália: 1982) e Com as horas contadas (Inglaterra: 1988). Os capítulos do trabalho foram publicados em forma de artigos acadêmicos (dois deles referenciados abaixo).

Além de teses, dissertações e artigos em eventos e revistas acadêmicos, a pesquisa das representações do jornalista no cinema tem ofertado trabalhos de conclusão de cursos de pós-graduação lato sensu e na graduação, alguns deles acessados durante a realização da pesquisa para esta revisão e registrados nas referências bibliográficas, mas se tornaria demasiado extenso para os propósitos deste artigo o detalhamento das suas produções.

\section{Uma proposta baseada na trajetória do herói}

Uma dificuldade recorrentemente apresentada por diferentes pesquisadores que se ocupam das análises de obras cinematográficas em geral, ou dos newspaper movies em particular, é a escolha da metodologia adequada para realizar de modo eficaz o empreendimento. Em alguns casos, a escolha metodológica nem mesmo fica clara, e é comum que se tenha uma leitura baseada em impressões esparsas sobre a produção fílmica e o papel da personagem jornalista em um determinado contexto histórico ou no universo diegético ${ }^{3}$ específico. O problema é antigo, quando se trata de cinema, tendo sido propostos e conhecidos vários caminhos de análise de filmes, como os presentes no

30 conceito de Diegese refere-se àquilo que é próprio do mundo interno da história narrada, seu tempo e seu espaço específicos, que se diferem do mundo externo, do mundo real. Para outras referências sobre o conceito, ver AUMONT E MARIE (2003: p. 77). 
Estudos em Jornalismo e Mídia - Vol. $10 \mathrm{~N}^{\circ} \mathrm{I}$ - Janeiro a Junho de 2013

livro "Ensaio sobre a análise fílmica", de Francis Vanoye e Anne Goliot-Lété, que teve a primeira edição francesa editada em 1992 (para este artigo, foi utilizada a segunda edição brasileira, de 2002. A primeira no Brasil é de 1994).

Citando Raymond Bellour, os autores lembram que:

\begin{abstract}
Enquanto a análise literária explica o escrito pelo escrito, a homogeneidade de significantes permitindo a citação, em suas formas escritas, a análise fílmica só consegue transpor, transcodificar o que pertence ao visual (descrição dos objetos filmados, cores, movimentos, luz etc) do fílmico (montagem das imagens), do sonoro (músicas, ruídos, grãos, tons, tonalidades das vozes) e do audiovisual (relações entre imagens e sons). Foi possível ver algumas análises perseguindo em vão o mito de uma descrição exaustiva do filme. Empreendimento evidentemente fadado ao fracasso. Se a complexidade do objeto-filme de fato conduz à colocação com rigor do problema de sua descrição pela linguagem e do que a ela se integra, sua natureza de pluralidade de códigos proíbe pensar em qualquer "reprodução verbal". (VANOYE e GOLIOT-LÉTÉ, 2002: p. 10).
\end{abstract}

Esta primeira dificuldade, situada pela obra entre os "obstáculos de ordem material", se soma a diversas outras enumeradas pelos autores, que não seria pertinente aqui reproduzir. $\mathrm{O}$ que se busca salientar é que não são poucas e nem pequenas as dificuldades dos que se dispõem a realizar este tipo de análise, o que não pode ser diferente entre os que se ocupam dos newspaper movies.

Nas pesquisas na área de Comunicação Social no Brasil, têm sido referências as orientações contidas em obras do campo metodológico, como as constantes do capítulo sobre "leitura e análise da imagem", de Iluska Coutinho, no livro "Métodos e Técnicas de Pesquisa em Comunicação", organizado por Jorge Duarte e por Antonio Barros; ou as presentes nas minuciosas descrições dos diferentes métodos e tendências de pesquisa enumerados por Santaella em "Comunicação e Pesquisa" (2002); ou, ainda, nos que buscam a transposição de procedimentos de pesquisa de objetos do jornalismo para o caso das análises fílmicas, como é o caso da utilização da análise de conteúdo, que mereceu capítulo de Heloíza Golbspan Herscovitz no livro "Metodologia de Pesquisa 
em Jornalismo", organizado por Cláudia Lago e por Marcia Benetti, entre outros.

Para somar a estes esforços no campo da Comunicação, a hipótese que levanta este artigo é a da aplicabilidade de um método de análise das narrativas clássicas, notadamente a presente no consagrado estudo sobre histórias e mitos populares empreendido por Joseph Campbell na década de 40 do século XX, já replicada para o caso do cinema por Christopher Vogler nos anos 90 e, no Brasil, utilizada em estudos do campo do Jornalismo Literário, como o que foi desenvolvido por Mônica Martinez, em tese de doutoramento orientada por Edvaldo Pereira Lima, que se tornou o livro "Jornada do Herói: a estrutura narrativa mítica na construção de histórias de vida em jornalismo" (2008).

No conhecido caso de Campbell, a contribuição se constitui no vasto levantamento de histórias populares em vários cantos do mundo, em diferentes épocas, e a constatação de que todas seguiam de modo muito aproximado um fio condutor comum, baseado na trajetória do herói, com as suas diferentes etapas narrativas. Vogler, experiente roteirista de Hollywood, incorporou os ensinamentos de Campbell para o cinema, ao verificar que, também nos filmes, era praticamente onipresente a estrutura da narrativa clássica. Com algumas adaptações no que o autor chama de "jornada do herói”, ele propôs um método útil para escritores (na acepção norte-americana, aqueles que labutam com a palavra profissionalmente em larga escala, como operários roteiristas, diferentemente dos "autores", mais próximos dos artistas), enumerando 12 etapas que o herói deve percorrer para que a narrativa obtenha sucesso junto ao público.

Já Martinez, integrante de um grupo ligado à Academia Brasileira de Jornalismo Literário, experimentou a utilização do método na apuração jornalística, transpondo para o real a forma ficcional de contar histórias de heróis (no seu caso, de modo mais específico ainda, de heroínas). Seu objetivo é apresentado no início da sua obra:

É dentro desse contexto que se apresenta essa proposta de trabalho. 
Em primeiro lugar, visa estudar com profundidade a aplicação jornalística da Jornada do Herói, método desenvolvido pelo mitólogo norte-americano Joseph Campbell, utilizado na elaboração de roteiros cinematográficos dos Estados Unidos pelo consultor Christopher Vogler, e parte integrante do método idealizado pelo pesquisador Edvaldo Pereira Lima, o Jornalismo Literário Avançado. (MARTINEZ, 2008: p. 19)

A proposta que aqui se levanta é a de que este mesmo método seja utilizado para esquadrinhar a trajetória de personagens jornalistas nos newspaper movies (excetuandose documentários), de modo a encontrar um referencial seguro, ainda que limitado como, de resto, todo método o é -, para entender o papel do profissional em determinado universo diegético e obter o máximo possível de explicações sobre o modo como ele se desloca na trama, tomando decisões, fazendo opções, relacionando-se com outros arquétipos (considerando-se o caso dele ser o herói, como se relaciona com mentores, opositores, aliados, entre outros).

A ideia é particularmente eficaz no caso do cinema norte-americano, responsável pela maioria dos newspaper movies e francamente usuário contumaz do método da narrativa clássica. A centralidade norte-americana neste campo é inegável, como observado por Berger:

Ainda que grandes filmes de jornalista foram, também, produzidos na Itália, no Brasil, na França e na Alemanha, ninguém soube traduzir tão bem o imaginário coletivo que associa a profissão à investigação, à aventura, à independência, ao arrojo, e, igualmente, ao cinismo, à falta de escrúpulos, à arrogância, como o cinema americano. (BERGER, 2002: p. 17)

Senra também argumenta em torno do papel preponderante dos EUA nesta produção, justamente pela escolha deste modelo de narrativa, que encontra no personagem jornalista uma espécie eficaz de agente condutor da trama (como ocorre com outros tipos clássicos, como detetives e gangsters). A natureza da atuação do 
jornalista, e a sua suposta objetividade e compromisso com a verdade factual, conferem um referencial de verossimilhança para a história, necessária para criar um universo plausível a ser compreendido pelo espectador.

Quando se torna personagem, o jornalista tem o dom de assegurar, através da suposta justeza da sua visada, uma autenticidade que foi eleita, desde o início da história do cinema, como a maior aspiração das suas imagens. Como personagem do filme, a sua simples presença tem tido o dom de 'contaminar' as imagens que o acompanham, conferindo-lhes a caução de uma veracidade que o cinema sempre esteve preocupado em restaurar. Esta transparência, incorporada pela visão do jornalista, que faz com que as imagens do filme apareçam como pura 'emanação' do seu olhar, vem consolidar o seu caráter 'espontâneo' e 'sem artifício' - comumente considerado como um padrão de qualidade cinematográfica - que confortou ao longo do tempo a propagação do modelo hollywoodiano. (SENRA, 1997: p. 39)

Se é discutível que tal modelo de narrativa sirva, de fato, para dar conta da complexidade da vida real, pode ser menos questionável que se mostre eficaz na hora de dissecar as obras produzidas justamente a partir do seu modelo. Se os realizadores seguiram um roteiro que obedece aos preceitos da narrativa clássica, não há porque não utilizar a sua própria receita para desmontar o roteiro e encontrar os elementos que forem necessários para explicar qual o papel que o personagem jornalista desempenha na própria história criada. Pode-se, ponto a ponto da narrativa, entender quais são os elementos motivadores da ação do personagem jornalista, de modo a fazê-lo atender às exigências da ação fílmica. A cada ponto do roteiro, situa-se a necessidade de uma resposta a um preceito da narrativa clássica, e este momento é justamente o mais rico para verificar como reage o herói jornalista.

Não se trata, aqui, de advogar o receituário das 12 etapas preconizadas por Vogler para se produzir obras cinematográficas, mas apenas de atestar que, independentemente de qualquer discordância, esta é uma sequência utilizada por quase todos os filmes e séries produzidos com pretensões comerciais em larga escala, como é o caso de Hollywood. Se este é o caminho por eles seguido, tem-se ao menos conhecida 
uma espécie de ferramenta para "desmontar" o produto cinematográfico.

O método não elimina a necessidade de compreender a obra em seu contexto histórico e na proposta do seu realizador, evitando-se tanto quanto possível o erro de atribuir ao filme ou a personagens valores que poderiam não fazer sentido na época de realização do filme ou em seu universo diegético. Esta não é uma tarefa simples, na medida em que o que podemos chamar de "contexto" é, em larga medida, uma pressuposição de quem analisa, uma vez que é impossível reconstituir todas as reais intenções e todas as forças de influência que estão presentes em uma obra de arte.

Mas também em relação a isso a utilização do método pode ser útil, na medida em que se baseia em etapas testadas e utilizadas por décadas no cinema (ou por séculos nas histórias mitológicas, se aceitarmos o postulado de Campbell). Assim, um pesquisador poderá analisar, com significativa dose de objetividade, e com a utilização de uma ferramenta razoavelmente universal e atemporal, como o personagem jornalista respondeu a cada etapa da jornada. Segue um esquema básico da proposta:

\begin{tabular}{|l|l|l|}
\hline $\begin{array}{l}\text { As etapas da Trajetória } \\
\text { do Herói, segundo Vogler: }\end{array}$ & No que consiste? & $\begin{array}{l}\text { Que respostas são possíveis obter } \\
\text { na análise fílmica aqui proposta? }\end{array}$ \\
\hline $1-$ Mundo Comum. & $\begin{array}{l}\text { É o local físico ou psicológico onde o herói } \\
\text { se encontra fora de ação, normalmente em } \\
\text { conforto, protegido das intempéries que a } \\
\text { aventura lhe reserva. }\end{array}$ & $\begin{array}{l}\text { O que o filme considera "mundo } \\
\text { comum" para um personagem } \\
\text { jornalista? Uma redação? Sua casa, } \\
\text { quando fora da ativa? Um bar? }\end{array}$ \\
\hline $2-$ Chamado à Aventura. & $\begin{array}{l}\text { Alguém chama o herói a aventurar-se por } \\
\text { algo. }\end{array}$ & $\begin{array}{l}\text { O que seria capaz de tirar um } \\
\text { personagem jornalista da inércia? O } \\
\text { que pode ser considerado uma } \\
\text { aventura para ele? }\end{array}$ \\
\hline $3-$ Recusa ao Chamado. & $\begin{array}{l}\text { O herói resiste, mostra-se cansado ou } \\
\text { relutante. }\end{array}$ & $\begin{array}{l}\text { O que leva o personagem jornalista } \\
\text { a recusar um chamado? O que ele } \\
\text { teme? O que o fez perder a paixão } \\
\text { pela profissão? }\end{array}$ \\
\hline $\begin{array}{l}4-\text { Encontro com o } \\
\text { Mentor. }\end{array}$ & $\begin{array}{l}\text { Alguém o convence a deixar seu mundo } \\
\text { comum e abraçar a aventura. }\end{array}$ & $\begin{array}{l}\text { Quem é capaz de definitivamente } \\
\text { convencê-lo? Quem o influencia tão } \\
\text { fortemente? }\end{array}$ \\
\hline
\end{tabular}

4"Resumo baseado em VOGLER (2006). 
Estudos em Jornalismo e Mídia - Vol. $10 \mathrm{~N}^{\circ} \mathrm{I}$ - Janeiro a Junho de 2013

\begin{tabular}{|c|c|c|}
\hline $\begin{array}{l}5-\text { Travessia do } \\
\text { Primeiro Limiar. }\end{array}$ & $\begin{array}{l}\text { A aventura começa, com a saída do mundo } \\
\text { comum e a entrada em um ambiente hostil. }\end{array}$ & $\begin{array}{l}\text { O que costuma ser retratado como } \\
\text { Mundo Especial para os newspaper } \\
\text { movies? O Mundo do Poder? O } \\
\text { submundo do crime? Um jornal } \\
\text { decadente? }\end{array}$ \\
\hline $\begin{array}{l}6 \text { - Testes, Aliados, } \\
\text { Inimigos. }\end{array}$ & $\begin{array}{l}\text { Neste novo ambiente, o herói precisa saber } \\
\text { quem está a seu favor e quem está contra. } \\
\text { Por vezes, se engana, mas isso também faz } \\
\text { parte da aventura. }\end{array}$ & $\begin{array}{l}\text { Na sua travessia pelo Mundo } \\
\text { Especial, quem costuma se aliar a } \\
\text { ele? Quem o hostiliza? Quais são } \\
\text { seus inimigos declarados? }\end{array}$ \\
\hline $\begin{array}{l}\text { 7-Aproximação da } \\
\text { Caverna Oculta. }\end{array}$ & $\begin{array}{l}\text { O herói está próximo de um lugar ainda } \\
\text { mais perigoso, onde está a chave para a } \\
\text { resolução da trama. "O ponto mais } \\
\text { ameaçador do Mundo Especial". }\end{array}$ & $\begin{array}{l}\text { Qual é o lugar mais perigoso para } \\
\text { um personagem jornalista obter o } \\
\text { que deseja? O que ele encontra } \\
\text { nele? }\end{array}$ \\
\hline 8 - Provação. & $\begin{array}{l}\text { Aqui o herói é testado ao extremo, em } \\
\text { confronto direto com o seu principal } \\
\text { inimigo. O espectador, por vezes, é levado a } \\
\text { acreditar que o herói perdeu esta batalha. }\end{array}$ & $\begin{array}{l}\text { Quais são as forças mais elevadas } \\
\text { contra as quais ele luta? Como as } \\
\text { derrota? }\end{array}$ \\
\hline $\begin{array}{l}9 \text { - Recompensa } \\
\text { (Apanhando a Espada). }\end{array}$ & $\begin{array}{l}\text { Mas o herói sobrevive, e consegue o que } \\
\text { veio buscar. Normalmente, esta etapa é o } \\
\text { começo do clímax. }\end{array}$ & $\begin{array}{l}\text { O que normalmente busca o } \\
\text { personagem jornalista? Como ele } \\
\text { consegue obtê-lo? }\end{array}$ \\
\hline 10 - Caminho de Volta. & $\begin{array}{l}\text { Vencida a primeira grande batalha no } \\
\text { Mundo Especial, o herói precisa voltar para } \\
\text { o Mundo Comum, mas não será tão fácil. } \\
\text { Ele vai pagar caro por ter ido tão longe e } \\
\text { invadido a Caverna Oculta do inimigo. Mas } \\
\text { ele, mais uma vez, vence. }\end{array}$ & $\begin{array}{l}\text { Quais as forças mais ameaçadoras } \\
\text { que precisa enfrentar o personagem } \\
\text { jornalista para conseguir voltar para } \\
\text { o Mundo Comum com o seu } \\
\text { "tesouro"? }\end{array}$ \\
\hline 11 - Ressurreição. & $\begin{array}{l}\text { Ele consegue deixar a Caverna Oculta, mas } \\
\text { nunca mais será o mesmo. A experiência o } \\
\text { faz renascer, redescobrir-se. Ele voltará } \\
\text { para o Mundo Comum, mas como um outro } \\
\text { homem, muitas vezes curado dos seus } \\
\text { demônios interiores. }\end{array}$ & $\begin{array}{l}\text { Quais os demônios internos que ele } \\
\text { venceu? Quais os resultados } \\
\text { pessoais ou comunitários da sua } \\
\text { jornada? }\end{array}$ \\
\hline $\begin{array}{l}12 \text { - Retorno com o } \\
\text { Elixir. }\end{array}$ & $\begin{array}{l}\text { Ele está de volta ao Mundo Comum, para } \\
\text { ser celebrado pelos seus pares, mas terá que } \\
\text { provar que esteve no Mundo Especial, e } \\
\text { apresentará algo que trouxe da sua jornada. } \\
\text { Pode ser um tesouro, em filmes de } \\
\text { aventura, ou a publicação de uma grande } \\
\text { reportagem no caso de newspapers movies. }\end{array}$ & $\begin{array}{l}\text { Uma vez de volta, o que apresenta } \\
\text { como prova da sua jornada? O que } \\
\text { o consagra ou cura as suas feridas? }\end{array}$ \\
\hline
\end{tabular}

\section{Considerações finais}

A simplicidade do esquema de análise aqui proposto, que pode ser adaptado a diferentes interesses de pesquisa, possibilita a sua utilização em diversos níveis de 
profundidade, com alternativas de experimento já na graduação, mobilizando alunos iniciantes em pesquisa científica a buscarem respostas às perguntas aqui propostas em vários filmes que tenham personagens jornalistas (ou o jornalismo, como instituição) como protagonistas. Suas limitações, e certamente não serão poucas, podem ser compensadas com a objetividade dos dados encontrados e com os cruzamentos possíveis a partir das respostas encontradas em um número significativo de filmes de um determinado universo recortado.

Deste modo, seria possível conhecer, por exemplo, quais os chamados mais comuns à aventura jornalística em filmes de uma determinada década, ou de um determinado diretor, ou de um determinado movimento estético, ou de um determinado país. Ou, ainda, quais as recompensas mais buscadas pelos personagens jornalistas, a que elas se referem, como foram obtidas, ou quais as consequências dos seus feitos "heróicos" para a sociedade.

Enfim, as possibilidades são muitas. Resta agora testá-las e aperfeiçoá-las, tarefa para todos os que se dispuserem a experimentá-las. 


\section{Referências Bibliográficas}

AUMONT, Jacques e MARIE, Michel. Dicionário Teórico e Crítico de Cinema. Campinas, SP: Papirus, 2003.

BERGER, Christa (org). Jornalismo no Cinema: Filmografia e Comentários. Porto Alegre: editora da Universidade Federal do Rio Grande do Sul, 2002.

BREA, Joana. Cinema e construção de subjetividades: a análise do discurso em Clube da Luta. Ciberlegenda, n 16. Niterói, RJ: Revista do Programa de Pós-Graduação em Comunicação da Universidade Federal Fluminense, 2006.

CAMPBELL, Joseph. O Heroi de Mil Faces. 11ª Ed. São Paulo: Pensamento, 1995.

CAMPOS SILVA, André; SANTOS SILVA, Antônio Manoel dos. As Bases Representacionais do Gângster Cinematográfico. Revista Eco-Pós v. 13, n. 2. Rio de Janeiro: Publicação da Pós-Graduação em Comunicação e Cultura da Escola de Comunicação da UFRJ, 2010.

CARVALHO, Cid Vasconcelos de. Aspectos do Nacionalismo no Cinema Brasileiro. Revista Ciberlegenda, $n$ 13. Niterói, RJ: Revista do Programa de Pós-Graduação em Comunicação da Universidade Federal Fluminense, 2004.

CHRISTOPHER, Vogler. A jornada do escritor - Estruturas míticas para escritores. $2^{\mathrm{a}}$ Edição. Rio de Janeiro: Nova Fronteira, 2006.

CODATO, Henrique. Cinema e representações sociais - alguns diálogos possíveis. Verso e Reverso vol. XXIV, n. 55. São Leopoldo, RS: Publicação da Universidade do Vale do Rio dos Sinos, 2010.

DUARTE, Jorge; BARROS, Antonio (orgs). Métodos e técnicas de pesquisa em comunicação. São Paulo: Atlas, 2008.

FERREIRA, Ricardo Alexino. Do discurso frankfurtiano ao do newsmaking: a construção simbólica do jornalismo no cinema. In: GOULART, Jefferson O. (org.). Mídia e Democracia. São Paulo: Annablume, 2006. p. 139-148.

LAGO, Cláudia. De romântico e de louco... reflexões sobre o romantismo jornalístico. In: Recife: Anais do XII Encontro Nacional da Associação de Programas de Pós Graduação em Comunicação, 2003.

Ethos romântico jornalístico e cinema. Recife: Anais do $5^{\circ}$ Encontro Nacional de Pesquisadores em Jornalismo - Universidade Federal de Sergipe, 2007.

Vozes, 2008.

; BENETTI, Marcia. Metodologia de Pesquisa em Jornalismo. $2^{\mathrm{a}}$ Edição. Petrópolis, RJ:

LOBO, Julio Cesar. Eurocentrismo, Política Externa Norte-Americana e Fundamentalismo Islâmico no Filme Inglês Com as horas contadas. Salvador: Revista da FAEEBA - Educação e Contemporaneidade, v. 12, n. 19, p. 147-158, 2003.

O dia em que Simmel foi às Arábias. Aspectos formais do estrangeiro, convenções de gêneros e padrões de recepção no filme Passageiro, Profissão: Repórter. Salvador: Contemporanea, vol. 2, n. 1, p 115-138, 2004. 
Estudos em Jornalismo e Mídia - Vol. $10 \mathrm{~N}^{\circ} \mathrm{I}$ - Janeiro a Junho de 2013

MARTINEZ, Mônica. Jornada do Herói: a estrutura narrativa mítica na construção de histórias de vida em jornalismo. São Paulo: Annablume, 2008.

NOGUEIRA, Lisandro. Cinema e Jornalismo: o melodrama e a tragédia moderna. Revista Esfera Ano 1 Vol. $1 \mathrm{n}^{\circ} 2,2008$.

OLIVEIRA, Paula Graziela; NOGUEIRA, Dayane; REIS, Talita Martins dos. Jornalismo no Cinema: Uma representação do fazer e ser jornalista. Caxias do Sul, RS: Anais do XXXIII Congresso Brasileiro de Ciências da Comunicação, 2010

PAIVA, Cláudio Cardoso de. Os jornalistas, a televisão e outras mídias no cinema: um estudo de ética e representação na arte cinematográfica. Revista FAMECOS, n 32, Porto Alegre: 2007.

PEREIRA, Reinaldo Maximiano. O trabalho jornalístico como elemento de composição ficcional no cinema americano. Coronel Fabriciano (MG), Complexus, v. 1, p. 8, 2003.

SANTAELlA, Lucia. Comunicação e Pesquisa: projetos para mestrado e doutorado. São Paulo: Hacker Editores, 2001.

TRAVANCAS, Isabel Siqueira. Jornalista como personagem de cinema. Campo Grande (MS): Anais do XXIV Congresso Brasileiro de Ciências da Comunicação, 2001.

O mundo dos jornalistas. São Paulo: Summus, 1993.

ROSA, Rachel Bezerra Abrantes. O Personagem Jornalista na Visão Cinematográfica da Década de 90. Brasília: Monografia de conclusão de curso de graduação no Centro Universitário de Brasília UniCEUB - Faculdade de Ciências Sociais Aplicadas - FASA, 2006.

RÜDIGER, Francisco. O cinema e o amor: romantismo de consumo e intimidade reflexiva. Rio de Janeiro: Revista Alceu, v. 10 - n.19 - p. 33 a 47, 2009

SENRA, Stella. O Último Jornalista: imagens de cinema. São Paulo: Estação Liberdade, 1997.

VADICO, Luiz. Cristologia fílmica: subsídios teóricometodológicos para a análise da produção de imagens cristológicas geradas no cinema e na TV. Rio de Janeiro: Revista Alceu - v.9 - n.17 - p. 47 a 63 , 2008.

VANOYE, Francis e GOLIOT-LÉTÉ, Anne. Ensaio sobre a análise fílmica. $2^{\text {a }}$ Edição. Campinas (SP): Papirus, 2002.

VOGLER, Christopher. A jornada do escritor - Estruturas míticas para escritores. 2a Edição. Rio de Janeiro: Nova Fronteira, 2006.

Este artigo e todo o conteúdo da Estudos em Jornalismo e Mídia

estão disponíveis em http://www.periodicos.ufsc.br/index.php/jornalismo/index

Estudos em Jornalismo e Mídia está sob a Licença Creative Commons 